Geopolítica(s) Revista de estudios sobre espacio y poder ISSN: 2172-3958

http://dx.doi.org/10.5209/rev_GEOP.2016.v7.n1.52951

\title{
En memoria de Edward W. Soja ${ }^{1}$
}

Equipo de la Asociación Americana de Geógrafos

Cómo citar: Equipo de la Asociación Americana de Geógrafos (2016) "En memoria de Edward W. Soja”. Geopolítica(s). Revista de estudios sobre espacio y poder, vol. 7, núm. 1, 15-18.

Tras una larga lucha contra la enfermedad, Ed Soja, Distinguido Profesor Emérito de Planificación Urbana de UCLA y conocido por sus importantes contribuciones a la geografía política posmoderna y a la teoría urbana, murió el pasado 2 de noviembre de 2015.

Edward William Soja nació el 4 de mayo de 1940 en una familia de inmigrantes polacos y creció en el barrio neoyorquino del Bronx. Desde que tenía diez años ya era todo un "geógrafo de la calle" que "se nutría de la densa diversidad" del barrio (cubierta del libro Thirdspace), experiencias que sin duda tuvieron una influencia decisiva en la configuración de la imaginación geográfica del autor en torno a lo urbano.

Soja fue alumno de Syracuse University donde recibió clases de, entre otros, Eduardo Mondlane, el primer mozambiqueño en alcanzar el título de Doctor y el fundador del movimiento de liberación de Mozambique, FRELIMO. En Syracuse, Mondlane desarrolló el plan de estudios sobre África Oriental, por el cual Soja sintió una fuerte atracción y al cual se unió.

A principios de los años 60, Soja fue a Kenia a estudiar planificación urbana en un momento en el que el país estaba inmerso en un proceso de transición desde formas tradicionales de organización social a formas sociales, económicas y políticas más modernas. Cuando terminó el trabajo de campo y regresó a Estados Unidos en febrero de 1965, impartió cursos sobre África Oriental y sobre técnicas de análisis cuantitativo.

Con el título de "La geografía de la modernización en Kenia: Un análisis espacial del cambio social, económico y político”, finalizó su tesis doctoral en 1967 y al año siguiente Syracuse University Press la publicó como parte de su serie geográfica.

En Northwestern University, donde ejerció como profesor asistente, continuó su especialización en la geografía política de la modernización y la construcción nacional en África. Durante los siete años que estuvo en Northwestern también ejer-

1 Originalmente publicado en ingles: “In Memoriam: Edward W. Soja”. AAG Newsletter, Diciembre de 2015 [Puesto en línea el 17 de Diciembre de 2015. URL: <http://news.aag.org/2015/12/in-memoriam-edward-wsoja/>. Consultado el 20 de Mayo de 2016]. Traducido por Marina Díaz. Reproducido con permiso. 
ció de profesor invitado en la Universidad de Ibadan (Nigeria) y la Universidad de Nairobi (Kenia).

En 1972 la Facultad de Arquitectura y Urbanismo de la Universidad de California en Los Ángeles (UCLA) lo fichó, y allí desarrolló el resto de su carrera. Fue allí también donde comenzó a orientar su investigación hacia el análisis de la reestructuración urbana en Los Ángeles y al estudio crítico de las ciudades y las regiones, interesándose, entre otras, por cuestiones de desarrollo, planificación y gobernanza regional, así como la espacialidad de la vida social.

Durante su larga y exitosa carrera como profesor en UCLA, Soja impartió cursos de grado y posgrado sobre temas como el desarrollo regional e internacional, economía política de la ciudad y teoría sobre planificación urbana. Asimismo, ejerció como director de tesis de muchos alumnos del departamento de planificación urbana, del que fue dos veces director. También ejerció como vicedecano durante nueve años.

Durante muchos años, Soja fue profesor visitante de la London School of Economics, más concretamente del Programa sobre Ciudades, un centro internacional dedicado al estudio de la sociedad urbana contemporánea, donde participó en el Máster sobre Diseño Urbano y Ciencias Sociales.

Soja fue uno de los máximos exponentes del llamado "giro espacial" en geografía, que se nutrió de los desarrollos procedentes de la teoría social crítica (incluida la economía política, el posmodernismo y la teoría de la cultura) para alumbrar novedosos análisis sobre las interacciones entre el espacio y la sociedad; especialmente sobre las luchas por el control del espacio en la ciudad y la emergencia de nuevas formas de urbanización.

Los Ángeles, una metrópoli enormemente diversa donde las desigualdades sociales y espaciales eran especialmente pronunciadas, fue objeto prioritario de su atención. A través del prisma conceptual de la espacialidad, trató de entender diferentes aspectos de la vida urbana (sus ritmos diarios, la división del trabajo, sus políticas públicas, la lucha por el lugar, y las relaciones entre habitantes dispersos).

La revista Annals of the Association of American Geogaphers publicó en junio 1980 su célebre artículo "The Socio-Spatial Dialectic” donde, tomando como referencia el trabajo del sociólogo urbano y marxista francés, Henri Lefebvre, y otros exponentes de la teoría social, defendió la idea de que la sociedad produce, organiza y da sentido al espacio, y al mismo tiempo son estas espacialidades las que dan forma a la sociedad y a las relaciones de producción.

El libro de Soja, Postmodern Geographies: The Reassertion of Space in Critical Social Theory (Verso, 1989) y el trabajo coetáneo de David Harvey, llamaron la atención acerca de que el posmodernismo era una nueva problemática sobre la cual los geógrafos debían tomar nota. Sus Geografías Posmodernas le garantizaron una buena dosis de atención mundial y le convirtieron en uno de los teóricos líder en la disciplina.

Una de sus mayores contribuciones a la teoría espacial y al campo de la geografía cultural fue su lectura de Lefebvre, autor de The Production of Space (1974), cuyo concepto de "triada espacial" fue reelaborado por Soja como una "trialéctica espacial" que incluía un "tercer espacio", o espacios que son al mismo tiempo reales e imaginados. Estas ideas vieron la luz en otros dos libros: Thirdspace: 
Journeys to Real-and-Imagined-Places (Blackwell, 1996) y Postmetropolis: Critical Studies of Cities and Regions (Blackwell, 2000).

Soja también trabajó con Allen J. Scott en la edición de un volumen sobre The City: Los Angeles and Urban Theory at the End of the Twentieth Century (University of California Press, 1996) en el que reunieron una serie de ensayos escritos por expertos en planificación urbana, arquitectura, geografía y sociología, dedicados a explorar la construcción del entorno y las dinámicas urbanas de Los Ángeles, llamando especialmente la atención sobre los tremendos cambios que habían tenido lugar desde los años sesenta.

Más recientemente escribió Seeking Spatial Justice (University of Minnesota Press, 2010) donde ofrecía nuevas maneras de entender y transformar las injustas geografías en las que vivimos; y, My Los Angeles: From Urban Restructuring to Regional Urbanization (University of California Press, 2014), que cubría más de cuatro décadas de desarrollo urbano en Los Ángeles y otras regiones urbanas.

El trabajo de Soja destaca por la intensa interacción entre teoría y práctica. Así, sus interpretaciones teóricas sobre el lugar, la localización, el paisaje, la ciudad y la región estaban ancladas en su investigación sobre la configuración del espacio y la sociedad en Los Ángeles, incluido el ascenso de la ciudad-región, la recuperación de los centros urbanos, y los movimientos sociales que defendían el derecho a la ciudad.

En 2013, la Asociación Americana de Geógrafos concedió a Soja una distinción por sus logros que reconocía su contribución pionera a la teoría geográfica y los estudios urbanos, especialmente sus ideas sobre la importancia del espacio para entender la sociedad y la ciudad, y sus ideas acerca de la posmodernidad y la metrópoli de Los Ángeles. La ocasión para la presentación del premio, en la reunión anual de la Asociación ese mismo año en Los Ángeles, no pudo ser más acertada.

En 2015, Soja recibió el premio Vautrin Lud, considerado como el Premio Nobel de la Geografía, por el que se distinguía la carreara de un destacado geógrafo cuya obra ha tenido una gran influencia dentro y más allá de la disciplina. Desafortunadamente, Soja no pudo estar presente en la entrega del premio en Saint-Dié (Francia) en octubre de 2015, pero su trabajo fue discutido en una mesa redonda donde participaron muchos de sus colegas internacionales.

No resulta fácil resumir la carrera de este hombre excepcional que comenzó con el análisis de la modernización en Kenia y transitó hacia el estudio de la posmodernidad en Los Ángeles. Fue uno de los defensores más apasionados y brillantes de la geografía humana. Su trabajo reconfiguró los estudios urbanos. Sus escritos sobre el espacio, la justicia espacial, y las ciudades han sido fuente de inspiración para muchos; y su pensamiento crítico continúa alimentando nuevas líneas de investigación orientadas a la comprensión teórica y práctica de las ciudades y regiones contemporáneas.

A lo largo de este camino tanto estudiantes como colegas han encontrado en su pasión y entusiasmo por la teoría, la crítica, las ciudades y la justicia social una fuente de motivación para sus investigaciones. Al recordar el año sabático que Soja pasó en la Universidad de Cambridge, Derek Gregory afirmaba que "Ed dio mucha vida al Departamento de Geografía, y deleitó a los estudiantes de posgrado con su sana irreverencia, su sentido de la aventura intelectual, y el indisimulado disfrute 
que le brindaba pasar tiempo con ellos”. Deja un triste hueco entre muchos amigos que conocieron su cálida y generosa personalidad. 